\title{
CAESAREAN SECTION THE RISING TREND: A RETROSPECTIVE STUDY
}

\author{
Shivaji Neelgund ${ }^{1}$, Hiremath P. B ${ }^{2}$
}

1 Department of Obstetrics and Gynaecology, SVMCH \& RC, Ariyur, Pondicherry.

2Department of Obstetrics and Gynaecology, SVMCH \& RC, Ariyur, Pondicherry.

\section{ABSTRACT}

\section{BACKGROUND}

The incidence of Caesarean delivery has risen alarmingly in both high income countries like Australia and USA and also in low income countries like Latin America and Asia. The objective of this, study is to analyse the factors affecting the rising trend of Caesarean Delivery and to critically derive at measures that can be taken to reduce this rising trend.

\section{METHODS}

This is a retrospective study conducted in the Department of Obstetrics and Gynaecology at SVMCH and RC, Ariyur, Pondicherry, of 1337 patients who underwent Caesarean Delivery between 2011 and 2013.

\section{RESULTS}

In our study, the incidence of Caesarean Delivery was 26.28\%, 1337 cases out of total 5880 deliveries. Out of these, Primary Caesarean Delivery was $44.58 \%$ [596 cases] and Previous Caesarean Delivery was 55.42\% [741 cases]. The incidence of elective CS was $11.29 \%$ and emergency CS was $88.63 \%$.

\section{CONCLUSIONS}

By a well-defined protocol, promoting institutional deliveries, proper monitoring of maternal and foetal parameters, encouraging deliveries by trial of VBAC and by proper counselling of the patients an optimal CS rate can be achieved.

\section{KEYWORDS}

Caesarean Delivery, Indications, Foetal Distress, Previous Caesarean, VBAC.

HOW TO CITE THIS ARTICLE: Neelgund S, Hiremath PB. Caesarean section the rising trend: a retrospective study. J. Evolution Med. Dent. Sci. 2016;5(50):3191-3194, DOI: 10.14260/jemds/2016/740

\section{INTRODUCTION}

Caesarean delivery which has significantly reduced Maternal and Neonatal Mortality, both in the developed and developing countries is now being labelled as the latest example of medicalization due to its rising incidence. ${ }^{1}$ The incidence of Caesarean delivery has risen alarmingly in both high income countries like Australia and USA and also in low income countries like Latin America and Asia.2,3 The WHO, 1994 has revised its guidelines - beyond a rate of $5-15 \%$, CS [caesarean section] has no additional benefits to the mother or the neonate. The optimal rate is not known. The world regions can set at $5 \%-15 \%$ or set their own standard, WHO - 2009.

The reasons for the increased rate of CS are not clear. Studies point to medical explanations for the safety of the mother and child in presence of obstetric complications. ${ }^{3}$ The non-medical explanations are preference of women who are taking informed decisions, institutional births demographic profiles of mothers, litigation problems, insurance facilities, private health care system, maternal request and personal society reason - fear of labour pain..$^{4,2}$

Mishra and Ramanathan reported in 2002 that the CS rate was $15 \%$ in two states and less in others. ${ }^{3}$ Pahari and Gosh 1997 reported that in a teaching hospital in Kolkata, between

Financial or Other, Competing Interest: None.

Submission 05-05-2016, Peer Review 31-05-2016,

Acceptance 06-06-2016, Published 22-06-2016.

Corresponding Author:

Dr. Shivaji Neelgund,

Department of Obstetrics and Gynaecology,

SVMCH \& RC, Ariyur,

Pondicherry-605102.

E-mail: shivajineelgund5@gmail.com

DOI: $10.14260 /$ jemds/2016/740
1990 - 1995, the CS rate was 50\%.5 Kambo et al reported in 2002 that in 30 medical colleges, the CS rate had increased from $21.8 \%$ from $1993-94$ to $25.4 \%$ from $1998-99.6$ Sreevidya and Sathyasekaran in 2003 reported that in Chennai between June 1997 and May 1999, the CS rate was 32.6\%.7 The least CS rate by DLHS 2007-09, NFHS was $4.5 \%$ in Jharkhand and Bihar. However, Maternal and Neonatal mortality was high in this region due to lack of emergency obstetric care.

\section{AIMS AND OBJECTIVES}

This is a retrospective study conducted at SVMCH and RC, Ariyur, Pondicherry, of 1337 patients who underwent Caesarean Delivery between 2011 and 2013. The objective of the study is to analyse the factors affecting the rising trend of Caesarean Delivery and aim to critically derive at measures that can be taken to reduce this rising trend.

\section{MATERIAL AND METHODS}

This is a retrospective study carried out in the Department of Obstetrics and Gynaecology, SVMCH and RC, with the aim to analyse the changing trend in the indications for caesarean section. There were 1337 cases of CS. Patients included both registered and emergency cases. Demographic details of the patient were recorded including age, stature, parity, address, socioeconomic status. Patients were evaluated by recording their detailed personal and medical history, present and past obstetrics history and general and obstetric examination findings. Laboratory investigations, foetal ultrasound findings were studied. Labour progression notes, the partogram recordings and the foetal electronic monitoring recordings were critically analysed.

Indications of caesarean section was carefully scrutinized. If more than one indication was present, the highest risk factor 
was considered. Maternal and neonatal outcome were noted, specifically the birth weight and Apgar score. Blood transfusion if given was recorded with its indication.

\section{RESULTS}

In our study, the incidence of Caesarean Delivery was $26.28 \%$ - 1337 cases of CS out of total 5880 deliveries. Out of these, Primary Caesarean Delivery was $44.58 \%$ [596 cases] and Previous Caesarean Delivery was 55.42\% [741 cases], Table No. 1. The incidence of elective CS was $11.29 \%$ and emergency CS was $88.63 \%$, Table No. 2 . The registered cases were 575 [43\%] and Emergency cases were 762 [57\%] Table No. 3. The indications for CS are shown in Table No. 4 - Previous caesarean $55.42 \%$ followed by Foetal Distress 16\%. The maternal indications in descending order are - Previous CS, NPOL [No Progress of Labour], CPD [Cephalopelvic Disproportion], Toxaemia, APH [Antepartum Haemorrhage] and Medical disorders in pregnancy, whereas the Foetal indications in descending order are - Foetal distress, PROM [Premature Rupture of Membranes], severe oligohydramnios, Breech presentation, Twin pregnancy and Post-dated pregnancy. In the previous CS group the leading indication was Foetal distress followed by Scar tenderness, Failure of induction, NPOL, Meconium stained liquor, Oligohydramnios, Toxaemia, Breech presentation and APH, [Table No. 5]. The maximum number of CS were in the age group of 21-35 yrs. Maximum number of previous CS, which were taken up for repeat CS were in the age group 31- 35 yrs. 36.59\%, [Table No. 6].

\begin{tabular}{|c|c|c|}
\hline Indications & No. of Cases & $\%$ \\
\hline Primary Caesarean & 596 & 44.58 \\
\hline Previous Caesarean & 741 & 55.42 \\
\hline Total & 1337 & 100 \\
\hline $\begin{array}{l}\text { Table 1: L } \\
\text { Previous }\end{array}$ & $\begin{array}{l}\text { rimary and } \\
\text { an Delivery }\end{array}$ & \\
\hline
\end{tabular}

\begin{tabular}{|c|c|c|}
\hline Indications & No. of Cases & \% \\
\hline Elective CS & 152 & 11.37 \\
\hline Emergency CS & 1185 & 88.63 \\
\hline Total & $\mathbf{1 3 3 7}$ & $\mathbf{1 0 0}$ \\
\hline \multicolumn{2}{|c|}{ Table 2: Data of Elective and Emergency CS } \\
\hline
\end{tabular}

\begin{tabular}{|c|c|c|}
\hline Type of Cases & No. of Cases & $\%$ \\
\hline Registered cases & 575 & 43 \\
\hline Emergency admission cases & 762 & 57 \\
\hline Total & 1337 & 100 \\
\hline
\end{tabular}

\begin{tabular}{|c|c|c|}
\hline Indications & $\begin{array}{l}\text { No. of } \\
\text { Cases }\end{array}$ & $\%$ \\
\hline Previous Caesarean Delivery & 741 & 55.42 \\
\hline Fetal Distress & 214 & 16.00 \\
\hline No Progress of Labour & 83 & 6.21 \\
\hline Premature Rupture of Membranes & 67 & 5.01 \\
\hline Sever Oligohydramnios & 52 & 3.89 \\
\hline Cephalo-Pelvic Disproportion & 47 & 3.52 \\
\hline $\begin{array}{l}\text { Malpresentation/Breech } \\
\text { Presentation }\end{array}$ & 39 & 2.92 \\
\hline Severe Pre-Eclampsia & 34 & 2.55 \\
\hline Ante-Partum Haemorrhage & 27 & 2.02 \\
\hline Multiple Pregnancies & 15 & 1.12 \\
\hline Post-dated Pregnancy & 10 & 0.75 \\
\hline Medical Indications & 8 & 0.59 \\
\hline Total & 1337 & 100 \\
\hline \multicolumn{3}{|c|}{ Table 4: Indications of Caesarean Delivery } \\
\hline
\end{tabular}

\begin{tabular}{|c|c|c|}
\hline Indications & $\begin{array}{c}\text { No. of } \\
\text { Cases }\end{array}$ & $\mathbf{\%}$ \\
\hline Foetal Distress in Previous CS & 108 & 14.57 \\
\hline Scar Tenderness in Previous CS & 103 & 13.90 \\
\hline Failed Induction in Previous CS & 96 & 12.96 \\
\hline $\begin{array}{c}\text { Non-Progress of Labour In Previous } \\
\text { CS }\end{array}$ & 79 & 10.66 \\
\hline $\begin{array}{c}\text { Meconium Stained Liquor in } \\
\text { Previous CS }\end{array}$ & 78 & 10.53 \\
\hline Oligohydramnios in Previous CS & 71 & 9.58 \\
\hline $\begin{array}{c}\text { CPD in Previous CS } \\
\text { Cevere Pre-Eclampsia in Previous }\end{array}$ & 70 & 9.45 \\
\hline Breech Presentation in Previous CS & 45 & 7.02 \\
\hline $\begin{array}{c}\text { Ante-Partum Haemorrhage in } \\
\text { Previous CS }\end{array}$ & 39 & 6.07 \\
\hline Total & $\mathbf{7 4 1}$ & $\mathbf{1 0 0}$ \\
\hline Table 5: Indications in Previous Caesarean \\
\hline \multicolumn{2}{|c}{} \\
\hline \multicolumn{2}{|c|}{} \\
\hline
\end{tabular}

\begin{tabular}{|c|c|c|}
\hline Age in Years & No. of Cases & $\%$ \\
\hline $16-20$ years & 175 & 13.09 \\
\hline $21-25$ years & 254 & 18.99 \\
\hline $26-30$ years & 302 & 22.59 \\
\hline $31-35$ years & 389 & 29.09 \\
\hline $36-40$ years & 217 & 16.24 \\
\hline Total & 1337 & 100 \\
\hline
\end{tabular}

\section{DISCUSSION}

The incidence of Caesarean Delivery in our study is $26.28 \%$. Similar incidence is reported from Raipur, $26.2 \%{ }^{8}$ A similar incidence was also reported from Indonesia $29.6 \% .{ }^{9}$ and from Nepal 28.6\%. ${ }^{10}$ There is a global rise of CS - 25\% to $30 \%$ in both developed as well as developing countries as reported by Leitch C R Walters. ${ }^{11}$ This rise in the incidence of CS is due to indications, which are based on interventions by biomedical technologies such as Fetal electronic monitoring and Ultrasonography. There is an increase in labour induction and USG detection of IUGR, multiple gestation, severe oligohydramnios. In high risk obstetric population, caesarean delivery is indicated to avoid the continuation of pregnancy or the onset or the continuation of labour in the interests of the mother and fetus. Availability of well-equipped medical setups with skilled personnel such as neonatal intensive care units, blood-bank facilities, privatization of medical practice and availability of health insurance, medicolegal issues and governmental pressure of safe delivery are the factors responsible for doctor's preference for this surgical procedure.

This higher rate is also due to lower rate of instrumental vaginal delivery, higher CS rate in breech presentation and low rate of vaginal birth after caesarean delivery. In this modern era indications for caesarean section are constantly changing, influenced by the population served, availability of wellequipped medical set-ups and clinical skills. Growing CS trend is also due to increased demand by patient's families or maternal request following conception after treatment for infertility and precious pregnancies. ${ }^{12}$

The World Health Organization in June 2010 has altered its previous $5-15 \%$ CS rates and has stated - as there is no empirical evidence for an optimum percentage, what matters most is that all women who need caesarean sections receive them. Goals for achieving an optimal Caesarean delivery rate should be based on maximizing the best possible maternal and 
neonatal outcomes, taking into account available medical and health resources and maternal preferences.

SVMCH and RC is a rural referral centre and the CS incidence of $26.2 \%$ is partially due to the referred cases, which have been sent for CS. This is seen in the high rate of emergency admissions and emergency CS.

In our study, the leading indication of CS is previous CS 55.4\%. Similar incidence is being reported from USA. 13 China. ${ }^{14}$ and in South India. ${ }^{15}$ A primary CS puts the next pregnancy in an increased risk of repeat CS. In previous CS cases, the risks of maternal and fetal injuries during operative vaginal delivery, increased risk of rupture uterus and atonic post-partum haemorrhage in a long trial of vaginal delivery are the reasons obstetricians prefer a repeat CS and avoid or give a very short trial of VBAC [Vaginal birth after CS]. This leads to an increase in the CS rates, in previous CS and also in moderate-to-high risk pregnancies. ${ }^{16}$ McMohan et al reported an increase in the maternal and fetal morbidity in VBAC compared to repeat CS. ${ }^{17}$ whereas Gonen et al reported VBAC with well-defined protocol to be safer than repeat CS. ${ }^{18}$ Guise et al also reported VBAC safer. ${ }^{19}$

A previous CS may have added co-morbidities, which increases the incidence of repeat CS. ${ }^{20}$ Improved surgical techniques, availability of broad-spectrum antibiotics, blood transfusion facilities, intensive care units have made CS a safe procedure and there are maternal demands for CS of 23 to $38.9 \%$, which has increased the incidence of $\mathrm{CS}^{21}$ It is reported that VBAC trials with proper selection criteria and proper monitoring protocols can help in reducing the rate of CS.18,19

In our study the second largest contributor to the primary CS rate was foetal distress, $16 \%$ similar to other reports. $22,23,24$ Even in the previous CS group in our study the leading indication for repeat CS is foetal distress, $14.57 \%$. In our study, foetal distress was diagnosed by foetal monitoring Cardiotocography [CTG]. CTG usually overestimates fetal distress, because many gestational and antepartum factors influence the foetal response in the CTG. The accurate method of estimation of foetal distress is by foetal scalp $\mathrm{pH}$ estimation. ${ }^{15}$ Majority of the cases of foetal distress had poor Bishop Score 124 cases [57.9\%] and meconium stained liquor in our study. Twenty one cases had cord around the neck. In 58 [27.1\%] cases the Apgar score was 7-8 at birth and at 5 minutes, which suggests more careful diagnosis of foetal distress may help to reduce the incidence of CS.

NPOL [Non-Progress of Labour] was 6.21\%, which was due to failure of induction of labour and minor degree of Cephalopelvic Disproportion [CPD]. The incidence of PROM [Premature Rupture of Membranes] in our study was 5.01\%. Monitoring with partograph and timely judicious use of oxytocics will help to reduce the rate of CS in these cases. The incidence of CPD in our study is $3.52 \%$.

There were 52 cases [3.89\%] of severe oligohydramnios in our study with amniotic fluid index less than 5, most of these had poor Bishop score and were taken up for CS. An amniotic fluid index less than 5 usually leads to foetal compromise due to cord compression.

The incidence of Breech presentation, as an indication of CS, in our study is $2.92 \%$ [39 cases]. The babies were big, macrosomia 28 cases, footling in 7 cases and 4 of the patients had Pre-Eclamptic Toxaemia [PET] all were delivered by CS. As reported by Hannah et al, perinatal mortality and neonatal morbidity are significantly reduced by CS. 25 The 34 cases of
Toxaemia were delivered by CS, as they had aggravating PET and changes were found in foetal Doppler studies. Antepartum haemorrhage cases were 27, of which 16 were placenta previa and 11 were abruption placenta. Considering maternal and foetal well-being, all were delivered by CS. There were 15 cases of twins, of which 12 had first baby in Breech presentation and 3 were preterm; therefore, all were delivered by CS. The 10 cases of post-dated pregnancies were delivered by CS. There were 8 cases of medical disorders complicating pregnancy. Gestational diabetic patients were 6, of these 3 had big babies, 3 had conceived after treatment for infertility. Two others cases had bronchial asthma.

Among the previous CS, the main indication was by Fetal distress [14.57\%] followed scar tenderness [13.90\%] and failed induction of labour [12.96\%]. Maximum number of CS was in the age group of 21 to 35 years. The peak incidence was in the age group of 31 to 35 years.

\section{CONCLUSION}

There is a worldwide increase in caesarean section due to various reasons and indications. Maternal and foetal welfare is very important in today's small family norm. This attitude has led to the emergence of a new set of indications in adopting CS as a preferred mode of delivery in moderate-to-high risk pregnancies and avoid difficult, manipulative, instrumental vaginal deliveries. This attitude lies in both - today's obstetric population and the medical personnel. Rising rates of Caesarean section are also due to the frequent diagnosis of foetal distress on electronic heart rate monitoring. By a welldefined protocol promoting institutional deliveries, proper monitoring of maternal and fetal parameters, encouraging deliveries by trial of VBAC and by proper counselling of the patients an optimal CS rate can be achieved.

\section{REFERENCES}

1. Mukerji SN. Rising caesarean section rate. J Obstet Gynaecol India 2006;56(4):298-300.

2. Potter JE, Berquo E, Perpetuo I, et al. Unwanted caesarean sections among public and private patients in Brazil: prospective study. British Medical Journal 2001;323 (7322):1155-58.

3. Mishra US, Ramanathan. Delivery related complications and determinants of caesarean section rates in India Health Policy and Planning 2002;17(1):90-98.

4. Hopkins K. Are Brazilian women really choosing to deliver by caesarean? Social Science and Medicine 2000;51(5):725-40.

5. Pahari K, Ghosh A. Study of pregnancy outcome over a period of five years in a post-graduate institute of West Bengal. J Indian Med Assoc 1997;95(6):172-74.

6. Kambo I, Bedi N, Dhillon BS, et al. A critical appraisal of caesarean section rates at teaching hospitals in India. Int J Gynaecol and Obstet 2002;79(2):151-58.

7. Sreevidya S, Sathiyasekaran BWC. High caesarean rates in Madras (India): a population-based cross-sectional study. BJOG: an International Journal of Gynaecology and Obstetrics 2003;110(2):106-11.

8. Singh Abha, Channawar Reema. A recent way of evaluating caesarean birth. J Obstet Gynaecol India 2009;59(6):547-51. 
9. Festin MR, Laopaiboon M, Pattanittum P, et al. Caesarean section in four south east Asian countries: reasons for, rates, associated care practices and health outcomes. BMC Pregnancy and Childbirth 2009;9:17.

10. Chhetri S, Singh U. Caesarean section: its rates and indications at a tertiary referral center in eastern Nepal. Nepal Journal Online 2011;9(3):179-83.

11. Leitch CR, Walkers JJ. Caesarean section rates. Evaluate the reasons for surgery. BMJ 1994;308(6921):133-34.

12. Ghosh S. Increasing trend in caesarean section delivery in India: role of medicalisation of maternal health. In: Ghosh S, eds. Working Paper 236. Bangalore: The Institute for Social and Economic Change 2010:1-16.

13. Emma L, Lisbet L, Kathleen B, et al. Contributing indications to the rising caesarean delivery rate. Obstet Gynaecol 2011;118(1):29-38.

14. Wang CP, Tan WC, Kanagalingam D, et al. Why we do ceasears: a comparison of trends in caesarean section delivery over a decade. Ann Acad Med Singapore 2013;42(8):408-12.

15. Unnikrishnan B, Rakshith $\mathrm{P}$, Aishwarya A, et al. Indications for caesarean section in a tertiary care obstetric hospital in coastal south India. Australasian Medical Journal 2010;3(12):821-25.

16. Mehta A, Apers L, Verstraelen $\mathrm{H}$, et al. Trends in caesarean section rates at a maternity hospital in Mumbai, India. J Health Popul Nutr 2001;19(4):306-12.

17. McMahon MJ, Luther ER, Bowes WA, et al. Comparison of a trial of labor with an elective second caesarean section. N England J Med 1996;335(10):689-95.
18. Gonen R, Tamir A, Degani S, et al. Variables associated with successful vaginal birth after one caesarean section: a proposed vaginal birth after caesarean section score. Am J Perinatol 2004;21(8):447-53.

19. Guise JM, Eden K, Emeis C, et al. Vaginal birth after caesarean: new insights. Evidence Report/ Technology Assessment Journal 2010;191:1-397.

20. Feng $\mathrm{XL}, \mathrm{Xu} \mathrm{L}$, Guo $\mathrm{Y}$, et al. Factors influencing rising caesarean section rates in China. Bull WHO 2012;90:30A-9A.

21. Wilkinson C, McIlwaine G, Boulton-Jones C, et al. Is a rising caesarean section rate inevitable? Br J Obstet Gynaecol 1998;105(1):45-52.

22. Liu S, Rusen ID, Joseph KS. Trends in caesarean delivery rates and indications for caesarean. J Obstet Gynaecol Can 2004;26(8):735-45.

23. Krychowska A, Kosinska K, KarwanPlonnska A. Comparison of indications for caesarean section in 198586 and 2000-01: analysis of changes. Ginekol Pol 2004;75(12):926-31.

24. Barber EL, Lundsberg LS, Belanger $\mathrm{K}$, et al. Indications contributing to the increasing caesarean delivery rate. Obstet Gynaecol 2011;118(1):29-38.

25. Hannah ME, Hannah WJ, Hewson SA, et al. Planned caesarean section versus planned vaginal birth for breech presentation at term: a randomised multicentre trial. Term breech trial collaborative group. Lancet 2000;356(9239):1375-83. 